\title{
The Self-Regulation of Electronic Commerce: An Appraisal in Accordance to the Chilean Law of Unfair Competition*
}

Submetido(submitted): 02/11/2015

Parecer(revised): 23/11/2015

Aceito(accepted): 22/01/2016

\author{
David López Jiménez ${ }^{* *}$ \\ Andrés Redchuk ${ }^{* * *}$ \\ Leonel Alejandro Vargas ${ }^{* * * *}$
}

\begin{abstract}
Purpose - Electronic commerce or e-commerce constitutes a commercial activity on the rise. Although it has many advantages, there are several lingering factors that prevent its consolidation, such as the lack of trust of the potential consumer/user. In order to overcome that obstacle, instruments of self-regulation were created in the field of advertising. Firms that wish to distinguish themselves favorably against their competitors have the option of adopting those instruments, which play a praiseworthy role regarding the target audience and constitutes a considerable improvement of consumer rights. However, on occasions, problems arise in the market when those systems of selfregulation bind third parties that did not voluntarily enter into a contract. This paper tackles the question of if self-regulation of advertising in the net can be put in place should it affects the honor of the third party not committed with the fair-practices document.
\end{abstract}

Methodology/approach/design - In this article, we will refer to the particularities that arise from a case concerning the Chilean Law no. 20,168, of 2007, on unfair competition and self-regulation of advertising in the Internet pertaining WOM, Movistar, Entel, Claro and Virgin.

Findings - The Chilean Law no. 20,168, of 2007 contributes to the goal of discouraging conduct contrary to good faith or good practices in advertising in conjunction with codes of conduct that have been approved in the field related to the systems of self-regulation.

Keywords: Self-regulation, competition, honor, freedom of expression, tutelage.

\section{Introduction}

In the past few years we have been experiencing a paradigm shift of the traditional consumer/user model. Social trends are shifting alongside with the arrival of new technology. Ever since the early 90s, when commercial

${ }^{*}$ This work was supported by Fondecyt 11130188 project.

${ }^{* *} \mathrm{PhD}$ (with European mention), Universidad de Sevilla (Spain), and PhD, Universidad Rey Juan Carlos (Spain). Research professor at the Universidad Católica del Norte, Antofagasta, Chile. E-mail: dlopezjimenez@gmail.com.

${ }^{* * *}$ Eng, MSc, PhD. Full professor. Enginering faculty. UNLZ. Argentina. Industrial engineer. Master of total quality. Master of ITC and computers. E-mail: andres.redchuk@gmail.com.

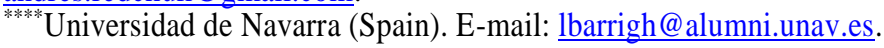


transactions through the internet were authorized, the challenges created by this channel of commerce are increasing at a fast pace.

Suppliers are also modifying the guidelines for action in the advertising of goods and/or services, which are offered in the market. Meanwhile, Internet users manifest distrust in the commercial communications received. In order to act accordingly, managers have differentiated themselves from their competitors through a system of self-regulation, which consists of a code of conduct and a control organism in charge of verifying its fulfillment. Their adhesion to such an instrument will involve certain obligations for the supplier, with certain advantages for the intended audience of the publicity carried out in cyberspace. Indeed, the advertising executed, in accordance to a predetermined code of good practice, will also have to be in accordance to rules and regulation as well as a set of ethical standards.

In this article, we address the characteristics and guarantees of selfregulation in electronic commerce. We will allude to the problem of digital advertising in electronic commerce alongside with contractual activities through digital channels. We will also examine the consequences which are derived from the failure to comply with the code of good practice. When the organization that controls the system of self-regulation give a determination on a case involving companies associated to the organization, it is expected that the aforementioned companies will comply voluntarily. However, in the scenario in which the system of self-regulation gives a determination against a company that is not committed to the system itself, we will study eventual repercussions on the afflicted rights. It should be noted that, in this case, we are dealing with a decision against non-committed third parties.

\section{Self-regulation of E-commerce}

E-commerce, in which interactive advertising is included, requires a regulatory framework that takes into account its global role as well as its defining peculiarities. In order to take them into consideration, as well as complying with current regulations, the agents that interact within this scope have approved an increasing set of self-regulation instruments. We will analyze several relevant aspects of that trend.

\subsection{Conceptual delimitation}

Self-regulation is not a new phenomenon. Any organization or person practices the act of self-regulation in one way or another. Such a fact is legally relevant when that self-regulation surpasses the private framework, projecting its effects across a notably ample radius, in some occasion even on a supranational level, attaining public powers (CANNATACI \& BONNICI 2003, 54).

The phenomenon of self-regulation unfolds between society and the state, between the private and public sectors. Also, self-discipline appears in the private sphere, but attains a public relevance. Based on the fact that selfregulation is a more informal practice than legislation and it lacks coercive 
capacity, its efficacy can be quite weak if it does not unfold in a culturally favorable environment and without the organization of all participants (DARNACULLETA 2009, 9).

It should be taken into account that self-regulation may be seen as an excuse that exempts the legislative power from their obligations. Regardless it may also be a complement to a legislation that inevitably cannot change its broad and ambiguous nature (NAVARRO 1990, 52).

From that perspective, self-regulation can offer solutions to specific problems that are established beyond legal norms, that could hardly be applied with their abstract general statements, in which most cases are unique cases of a group or a type of individuals that have their specific problems.

Self-regulation, in the field of advertising, is the ordinance made for the individuals that actively participate in the realization, execution and diffusion of interactive advertisements, in order to willingly impose a set of norms of good practice. Self-regulation is a word that implies on one hand a normative rule and, on the other hand, an internal volitional capacity of the participants who fulfill all the norms materialized in different documents of good practices such as a code of conduct (OGUS 1995, 100).

The advantages that are now being tested can provide the implementation of distinct techniques (BASEDOW 2000, 10). The instruments derived from self-regulation allow to swiftly adapting to technological, economical and sociological changes, a much quicker way to adapt than that obtained through more conventional channels of ordinance. This stands on notably significant data, in such a dynamic and changing sector, that is the internet. We do not find ourselves with a new problem due to the fact that traditionally legislation has solved problems on the application of new technology, albeit with some delay.

Such an inconvenience, intrinsic to the procedure of the creation of norms, could be avoided or at least diminished by adhering to the codes of conduct that regulates e-commerce, for in comparison with such norms of conventional origins, a result of self-regulation has a notably shorter time to be created and less formalized prerequisites, leading to a greater ease to adapt to changes in the technological area.

Other prerogatives of self-regulation that need to be highlighted are: flexibility, due to the fact they are in a constant state of technological flux; specialization, which favors the development of standard levels of correction; transparency; prevention of transgressions, especially if the self-regulation has valuation mechanisms in the case of interactive advertisements before they are aired; low costs in areas where transgression procedures allow to cover eventual pitfalls of legal nature; and easy accessibility.

\subsection{Guarantees}

A system of self-regulation should include elements that build a thorough and efficient backbone. The lack of some mandatory guarantees or the malfunction of such will determine that the system, besides inefficient, is in fact incomplete. Without a sound set of guarantees, that system does not meet the 
necessary requirements to be considered a true system of self-regulation, which will comply with state legislature (LÓPEZ 2014, 10). To talk about an efficient instrument of self-evaluation, some elements should be present as constitutive power, while others are accessories or complimentary.

The code of conduct or regulating document is a constitutive requirement. It is needed and should be presented, among other aspects, as an interactive advertising, making its online query possible, together with its constancy, in the languages of the place of the establishment of the firm. Another constitutive requirement is the acceptance of the parties to be bound by an alternative dispute resolution organization, which in such case imposes a decision that is legally binding on committed firms and customers. In so doing, the alternative dispute resolution technique designed for binding the parties will be applied upon an infraction to the code of conduct in which it is integrated, imposing a sanction according to the severity of the transgression.

Regarding ancillary prerequisites, the following two terms, among others, are worth mentioning. Firstly, all parties must accept the agreement which provide that, if a dispute should arise, it will be resolved by an alternative dispute resolution technique. Secondly, the deal must be accompanied by the seal of quality or trust mark of the company that holds it, representing the audits' recognition of the existence of guarantees of the company's commitment to the system.

However, we insist, those guarantees are not mandatory. Their incorporation to the system of self-regulation seems opportune for two reasons. On one hand, in the case in which the code of conduct counts with the approval of all potentially susceptible agents, achieving a general consensus, it will be considered as self-imposed, making the level of commitment higher than in the opposite case, for its composition will respond to the interests of all parties involved. On the other hand, the trust mark is the symbol that defines the business group that fulfills the good practices clause established in the code of ethics. It would suffice for the potential consumer to see and consequentially know its implication and meaning of the presence of the logo to be able to exercise its full potential for which it was conceived. The aforementioned set of guarantees validate the commitment to a concrete system of self-regulation and with it the set of improvements that are left to the disposition of the potential consumer/user.

\section{Incidence of the Chilean Law no. 20,169}

The managers that use internet to operate activities of online advertising can willingly commit to integrating themselves in a system of self-regulation with a document of fair practices.

However, in occasions, such as the recent case of Chile, some systems of self-regulation have affected third parties that had not manifested their willingness to adhere to such regulation.

According to article 3 of the Chilean Law no. 20,169, all conduct contrary to good faith or good practices, which through illegitimate means, 
pursues to steer consumers away from a market agent could be regarded as an act of unfair competition. The question to be solved is if such a behavior of selfregulation of advertising in the net can be put in place should it affects the honor of a third party not committed with the fair-practices document.

\subsection{Parties involved in the claims in the system of self-regulation}

Anyone can present a claim before the system of self-discipline. It may be a consumer on an individual manner, a business, a business association, a consumers association or the public sector. An example of the latter in Chile happened when Chile's Sernac formalized an agreement with the Board of Selfregulation and Advertisement Ethics (CONAR) with the objective that the publicity fulfills legal norms and ethical norms included in the code of fair practices of the system of self-discipline.

CONAR was conceived towards the end of the 80 s and represents a nonprofit organization sponsored and promoted by advertisers, agencies and media. Ever since the moment of its founding all the way to present day, it has decided over 900 cases. Additionally, since 2008, it is part of the EASA (European Advertising Standards Alliance), as well as CONARED, which constitutes the System or Organizations of Self-regulation in Latin America. Its actions are based on the Chilean Code of Advertising Ethics. Such code of conduct is inspired in the International Code of Advertising Practices of the International Chamber of Commerce. One of the regulatory matters of interest for the law on unfair competition is that of comparative advertising. We will discuss the topic later, for such self-regulation has been applied in cases of companies not committed to such a system.

In order to submit a complaint to CONAR, it is not imperative to be committed to the system of self-discipline. It represents a procedure that turns out to be free of cost for the consumers, organizations of the public sector and associates to the system of self-regulation. However the procedure is not free of cost for entities that are not part of it.

In any case, it is settled that, for the complaint to have grounds for admission, there has to be a relationship with the advertisement, in a way in which the resolution from CONAR affects the claimant.

\subsection{Complaints against companies voluntarily committed to the system}

The most common issue of using the system of self-regulation involves companies who have manifested the utmost desire of integrating that system (BLACK 1996, 28). In fact, the number of resolutions to third parties is notably lower or even inexistent in some systems of self-discipline in Latin America. However, the set of complaints against non-adhered third parties in the subject of interactive advertising does not result in an isolated incident under the Jurisdiction of CONAR-Chile. The resolutions given by that organization will 
be based on the codes of conduct of the system of self-discipline in the subject of interactive advertising.

The system of self-discipline will act against committed companies when the mediation has resulted in a transgression of the code. The latter is a medium for the resolution of the conflict, previous to the intervention of the body of control and optional for the parts that are handed to a third party with the role of determining the stances of each. The majority of the differences which, in the field of interactive advertising, exist between both parties are usually resolved through mediation, making it imperative to seek intervention of the organization of control in a relatively smaller percentage of cases (VÁZQUEZ 2011, 2737).

\subsection{Complaints against non-affiliated third parties: The eventual repercussions in respect to the right of honor}

The acceptance of any system of self-regulation has to be voluntary for the suppliers interested in it, making it inadmissible for the promoting entity to demand a non-affiliated entrepreneur to adhere to the norms stipulated in the code of conduct. In other words, when an entrepreneur does not commit to specific system of self-regulation and with it a corresponding ethical code, the promoting entity would not have the legal basis to demand its fulfillment.

Notwithstanding that consensus, it is possible that in certain controversies on internet advertising the system of self-regulation will act on some conflicts that involve non-adhered parties. Despite the voluntary nature of the system, that can only statutorily affect the affiliated entities, the moral force enjoyed by the action of certain systems of self-discipline is undeniable, as is the case of CONAR, in Chile. If a third party does not reject being subject to the system, it would enact a resolution.

Even in cases third parties not covered by the system, the claimant may solicit a ruling or non-binding ethical opinion about the advertisement of the non-affiliated party. It should be insisted that the decision will be expressed in a document, which will take the shape of an opinion, which will express its verdict which will not be binding for non-affiliated parties.

Taking into consideration that the ethical code, on which the system will base its valuation, include the current norm as well as numerous ethical considerations, the emitted ruling, as an opinion, will not be disassociated from what the judicial power could do if it were subjected to trial. In any case, it is convenient to insist that the ruling is non-binding for the company, whose conduct the system is acting upon, having, at all times, the freedom to act following their recommendations or not.

Such claims will not be at all binding for the non-affiliated party. The decision content is possible under the fundamental right of freedom of expression, recognized by article 19, subsection 1, of the Chilean Constitution, where an ideological freedom is protected which implicitly promotes the expression and dissemination of beliefs and value of judgments. In Chile that aforementioned precept imposes an obligation of guaranteeing the right of freedom of speech in both its facets. On one hand, it guarantees informing 
without censorship and, on the other hand, receiving information, in accordance to what Chile's Constitutional Court and its tribunals had set forth. The right of freedom of expression could find itself threatened by either the public sector or the private sector.

It should be warned that in the inter-American system freedom of expression presents a greater oversight than most systems of Human rights protection. In effect, the Inter-American Court points to this greater protection in the American Convention and other declarations in the Universal Rights such as the International Pact of Civil and Political Rights, and in the European Law, the European Convention for the Protection of Human Rights and of Fundamental Liberties.

Divergent views could be presented though. In fact, it could be considered that the system of self-regulation - more specifically the code of conduct in which the organization of control bases its resolutions when it comes to cases that relate to the internet - could even get to the point of breaking its principle of voluntary adhesion to the systems of self-regulation for two reasons. Firstly, due to the fact that the system allows the controlling body to process any failure to fulfill the code of ethics by non-affiliated firms and secondly, because with such behavior, it could encourage businesses to join the system of selfdiscipline.

Those divergent views are not mainstream views. On the consideration that the process created by the body of self-regulation enables the indictment of alleged breaches of the code by non-affiliated third parties, it should be warned that the declarations the organization of control emits, against firms not committed to the ethical code, constitute, in the case in which the non-affiliated party refuses to participate in the procedure, ruling or non-binding opinions, which are not publicized, unless publicized under the right of freedom of expression.

Such decisions have the value of mere opinions under the protection of freedom of expression of article 19.12 of the Chilean Constitution. Freedom of expression is the right through which ideological freedom is expressed on its positive side freely expressing thoughts and ideas. The right of freedom of expression includes the criticism of other's behavior, even when such an opinion is tasteless and could offend. This is how pluralism, tolerance and broadmindedness are required. Without them we cannot have a democratic society.

As we have stated earlier, CONAR has recently been forced to act against a non-affiliated business due to their aggressive comparative advertising carried out against other affiliated businesses. The Law no. 20,169 on unfair competition constitutes the first direct regulation to such advertising in Chile. Such rule considers comparative advertising as unfair competition in its article 4. It states that all false information or statements about the good, services, activities, logos, establishments or commercial relations of a third party, which are prone to impacting their reputation within the market, are acts of unfair competition. Statements intended to discredit or ridicule without an objective stance are illegal. The subsection to which we just referred to sanctions the 
conduct of disparaging advertising, which refers to goods, services or other elements linked to competition, with the goal of damaging its reputation.

Comparative advertising (unfair one) carried out by Nextel Chile, today dubbed WOM over its competitors - Movistar, Entel, Claro and Virgin - has a negative impact, in two huge respects. On one hand, it discriminates the image of women, and on the other it alludes to its competitors in a pejorative way. Given that the telecommunications company of which we are talking about did not go through CONAR's procedure, when Movistar and Claro presented a complaint, only an ethical opinion was declared in which it expressly states two transgressions of the good practice code, which regulates online advertising. Firstly, with respect to the presence of women in the advertisement, it is stated, on behalf of the self-discipline system, that the sensuality of women is a common advertising resource that is not reproachable per se, although it is reproachable when it is accompanied by other factors that make it ethically questionable and could even get to the point of undermining women. That happens when women are used in advertising showing their bodies in skim clothing, in suggestive and provocative situations with other women, in an environment that invites promiscuity, that sensuality transforms into something purely sexual which surpasses the limit of what is ethically acceptable. It is even more reproachable if it is exhibited and exposed to a juvenile audience, who are still very impressionable and their judgment has not fully been developed. Secondly, it is stated that the denigration of a competitor constitutes not only a huge offense to the professional honor of the advertiser; it also leads to a weakening of public trust towards advertising. In effect, it should be warned that one must not confuse being original or innovative with denigrating the competitor's brand. Such issue finds itself subject to the courts. In fact Movistar has recently presented a lawsuit against WOM.

In this last respect, honor should be highlighted, as well as the personality of the so-called goodwill or commercial credit (GÓMEZ 2010, 221). In the cases where it infringes the honor of an individual, it is an attack to the person and their inherent qualities (art 19.4 of the Chilean Constitution). However in the cases of denigration of firms, what is infringed upon is the market credit of a specific competitor (OTAMENDI 1998, 18), affecting their reputation (LARRAIN 2011, 162). Commercial honor can be seen as the professional prestige that the dealer has in the market, like an implicit right derived from her condition as a businesswoman, which is carried as a legal repercussion to her brand name. Such professional prestige of Movistar, Claro, Entel and Virgin was adversely affected by WOM. Even though the telecommunications company WOM resorted to comparative advertising, this turned out to be blatantly denigrating.

It should be stated that denigration constitutes a clear act of foul play with respect to a competitor that operates in the same market. However, it is also against the consumers which are obviously affected by this. Thus legislator attempts to protect rights of the consumers and users of forming an opinion and be able to adopt decisions in an adequate manner. To this end, it is convenient that the information related to the goods and services is trustworthy. 
The role of the organization of control as part of the system of selfregulation in the exercise of freedom of speech against the non-affiliated business impacts its honor. In fact, CONAR manifestation in an opinion of an ethical nature solely highlights the inadequacy of WOM's advertising to the code of good practices set by CONAR Chile. This document includes, besides the applicable norms, standards of deontological nature. CONAR Chile constitutes and association representative of the sector in which the most part of advertisers, agencies and State media are affiliated to.

CONAR expresses its opinions in the same way that any natural or legal entity can freely express their opinion on a matter of public interest, even when such assessment generates criticism of application to a third party. It cannot be denied or, even prohibit the possibility that a business association (CONAR Chile) who represents a considerable percentage of the advertising industry express their opinion on the ethical and deontological correction of a matter of public interest such as any situation that affect consumer or users, although that judgement implies an ethical or deontological reproach.

The content of such statement emitted without the purpose of competition, by CONAR, with respect to the non-affiliated entrepreneur to the system of self-discipline, would be assertions, truthful and relevant without incurring in disqualifications of any type. It cannot be reputed, in any case, and act of denigration carried out by the system of self-regulation. As we have previously seen, if the case submitted for the assessment of CONAR, were presented to the Tribunals, the verdict would not change.

\section{Conclusion}

Businesswomen are modifying their guidelines relating to the advertising of goods and services that they offer within the market. It turns out to be more frequent for them to manifest their commitment with a system of self-regulation that will allow them attaining a favorable differentiation from their competitors. The adhesion to such an instrument will entail a set of obligations for the supplier, but will also carry advantages for the addressee of the advertisement carried out in digital space. In fact, the advertisement will have to stick to predetermined code of good practices. It will also have to fulfill the current legal framework and considerable set of ethical standards.

The businesswomen who have voluntarily joined to a system of selfregulation have to be aware of the implications of such a choice. So, among other issues, they have to meet the standards set by the regulating code of good practice of the advertisements that they carry out. In the case in which they fail to fulfill the code, they will have to submit to the sanctions that the organization of control in charge of its regulation imposes.

The problem arises when the system of self-regulation acts against a nonaffiliated third party, who has not explicitly manifested his/her commitment to it. In such a case, an ethical opinion will be given. As we have seen from such a case, this is made possible thanks to freedom of expression. In the case of Chile, such situation was seen with respect to unfair comparative advertising carried 
out by the telecommunications company against its competitors. The aforementioned competitors, in good judgement, due to the fact that their honor affected and their name denigrated, resorted to the system of self-regulation dubbed CONAR. Such entity acted against WOM (non-affiliated) by virtue of an ethical opinion in which it exposed the practices that infringed the code of conduct in the area of advertising that exists in such system.

Businesses who do not have a good reputation in the economic field in which they act, encounters a considerable amount of obstacles for the realization of their activity. The Chilean Law no. 20,168, of 2007 contributes to the goal of discouraging conduct contrary to good faith or good practices in advertising in conjunction with codes of conduct that have been approved in the field related to the systems of self-regulation.

\section{References}

BLACK, J. Constitutionalising Self-Regulation. Modern Law Review, 1996: 24-55.

CANNATACI, J. \& Bonnici, J. P. Can Self-regulation Satisfy the Transnational Requisite of successful Internet Regulation. International Review of Law Computers, 2003: 51-61.

DARNACULLETA GARDELLA, M. M. La autorregulación y sus fórmulas como instrumentos de regulación de la economía. Revista General de Derecho Administrativo, 2009: 1-20.

FISS, O. Free Speech and Social Structure. Iowa Law Review, 1986: 14051425.

GÓMEZ GARRIDO, J. Derecho al honor y persona jurídica-privada. Revista del Departamento de Derecho de la Universidad de La Rioja: REDUR, 2010: 205-225.

LARRAIN PÁEZ, C. Algunas cuestiones relevantes sobre el derecho al honor y la responsabilidad civil en particular, sobre el daño moral, el artículo 2331 del código civil, y la legitimación activa. Revista Chilena de Derecho Privado, 2011: 143-189.

LÓPEZ JIMÉNEZ, D. La autorregulación de las TIC por parte de las empresas de economía social: D'confianza como modelo de referencia. Revista Internacional del Mundo Económico y Del Derecho, 2014: 1-28.

NAVARRO, P. E. La eficacia del Derecho. Una investigación sobre la existencia y funcionamiento de los sistemas jurídicos. Madrid: Centro de Estudios Constitucionales, 1990. 
OGUS, A. Rethinking Self-regulation. Oxford Journal of Legal Studies, 1995: 97-108.

OTAMENDI, J. La competencia desleal. Revista Jurídica de la Universidad de Palermo, 1998: 1-44. 
